\title{
METODOLOGIA PARA PLANEJAMENTO EM EAD UTILIZANDO ESTILOS DE APRENDIZAGEM, INTELIGENCIAS MULTIPLAS E COMPETENCIAS REQUERIDAS: UMA CONTRIBUIÇÃO AO APERFEIÇOAMENTO DE EMPREENDEDORES ${ }^{1}$
}

\author{
METHODOLOGY FOR PLANNING IN EAD USING LEARNING STYLES, \\ MULTIPLE AND COMPETENCIAS INTELIGENCIAS REQUIRED: A \\ CONTRIBUTION TO THE IMPROVEMENT OF ENTREPRENEURS
}

\begin{abstract}
Selma Regina Oliveira ${ }^{2}$ Edson Walmir Cazarini ${ }^{3}$

RESUMO: O presente documento propõe um suporte metodológico lastreado nos Fatores Críticos de Sucesso (FCS), Competências Profissionais Requeridas (CPR), Estilos de Aprendizagem (EA) e Inteligências Múltiplas (IM), que oriente a implementação de uma estratégia de planejamento em projetos de Educação à Distância (EAD), com vistas ao aperfeiçoamento de empreendedores. A pesquisa foi aplicada em dois cursos de PósGraduação - MBA em Administração, do Módulo Gestão de Empreendedores, de Instituições Públicas e Privadas, com uma amostra de 70 participantes. Este suporte metodológico contempla quatro fases: Na fase (1) são determinados os FCS de um projeto de EAD a partir da literatura especializada, Análise Ambiental e Consulta aos Especiaistas. Na fase (2) são determinados os EA dos alunos, por meio dos modelos de Felder e Soloman. Na fase (3) determinam-se as CPR dos alunos, utilizando-se a Técnica Delphi. Na fase (4) determinam-se as IM utilizando o modelo de GARDNER (1994). Por fim, priorizam-se, por importância, as CPR em relação aos FCS, e em seguida os EA e IM em relação às CPR. Com vistas a reduzir a subjetividade dos resultados apresentados, adotam-se os métodos multicriteriais Compromise Programming, Electre III e Promethee II e o método de Escalagem Psicométrica Lei dos Julgamentos Categóricos. Os resultados mostraramse satisfatórios, validando o suporte metodológico ora proposto.
\end{abstract}

PALAVRAS-CHAVES: Método - Educação a Distância - Estilos de Aprendizagem - Inteligências Múltiplas Competências Requeridas.

ABSTRACT: The balance between learning styles, multiple intelligences and required professional competencies is a way of promoting a higher chance of adaptation to everyday situations or work demands. This is the goal of this work, which proposes a method support system based on critical factors of success (CFS), required professional competencies (RPC), learning styles (LS) and multiple intelligences (MI). This method can guide the implementation of innovation strategies when planning distance education (DE) projects. It also presents a multiple-case study of DE Business Programs in private and public higher education institutions in Brazil. This methodological support comprises four phases. In Phase 1 CFS of a DE project are determined based on specialized literature, environmental analysis and experts' points of view. In Phase 2 the students' LS are assessed by means of Felder and Solomon's model. In Phase 3 the students' RPC are established via the Delphi technique. In Phase 4 the MI are ascertained through Gardner's model (1994). Finally, RPC are prioritized, in order of importance, vis-à-vis CFS; so are LS and MI regarding RPC. In order to reduce the subjectivity of results, the study adopts the multi-criteria methods Compromise Programming, Electre III and Promethee II and the psychometric scaling method Law of Categorical Judgments and multivariate cluster analysis. The results obtained have been satisfying, validating the proceeding proposed.

KEYWORDS: Method - Distance Education - Learning Styles - Multiple Intelligences - Required Competencies

\footnotetext{
${ }^{1}$ Artigo Recebido em 15.07.2010. Revisado por pares em 03.11.2010. Recomendado em 28.04.2011 por Leomar dos Santos Editor. Publicado em 28.07.2011.

Organização Responsável pelo periódico: Universidade regional de Blumenau - FURB - www.furb.br/rn
}

\footnotetext{
${ }^{2}$ Universidade Federal de Tocantins - UFT - selmaregina@webmail.uft.edu.br

${ }^{3}$ Universidade de São Paulo - USP - cazarini@sc.usp.br
} 


\section{TEMPOS DE DESAFIOS}

Recentemente o desenvolvimento de competências pessoais deixou de ser uma decisão pessoal e passou a ser estratégia das empresas. Respostas vêm sendo dadas a esses desafios. Apesar de ainda isoladas, certas proposições começam a ser incorporadas no meio acadêmico e empresarial, para redirecionar as questões de ensino e aprendizagem. E o fato das pessoas manterem-se atualizadas vem reforçar a importância da Educação a Distância (EAD) na formação continuada, reinserindo os indivíduos em novas sociedades construídas em torno da informação e do saber e colocando-a como uma das “mais notáveis” manifestação da mundialização.

O desenrolar de um projeto de EAD envolve uma diversidade de eventos de grande complexidade, num contexto de incerteza e risco, podendo afetar o fluxo do projeto, frustrando expectativas de estabilidade. Há de se ter em mente que os riscos podem advir de diversas origens e cenários, provocados por eventos ambientais ou advindos do próprio projeto. É necessário refletir no sentido de que a implementação de projetos de EAD não será simples e um dos principais focos refere-se à organização dos recursos utilizados para capacitar as pessoas afim de obterem competências necessárias com vistas a uma determinada performance de trabalho.

As características dos projetos diferem muito, sendo objeto de análise igualmente diferenciada. Além disso, a literatura ainda diverge no tocante a concepção da EAD. A boa prática recomenda o cumprimento de uma seqüência de ações articuladas, que consiste nas seguintes fases : A fase (i) contempla duas etapas: (1) - (i) planejamento das necessidades; (ii) institucionalização e formação da equipe de projetos e determinação dos procedimentos de comunicação (inclusive teste de mercado) ; (iii) consolidação dos objetivos, resultados e das metas de desempenho do projeto ; (iv) esboço do projeto de referência ; (v) estudo dos custos, receitas, fluxos de caixa ; (vi) estudo dos impactos sociais; (vii) análise, alocação e gestão de riscos (avaliação preliminar) ; e (viii) análise da viabilidade básica. Etapa (2): (i) refinamento do projeto; e (ii) refinamento do estudo de custos, dos impactos, e de riscos. Fase (ii); Desenvolvimento/Implementação; e evolução e continuação CARVALHO, 2001; KAYE, 1979; LAASER, 1997; LEVY, 1997).

De todos esses elementos resulta a atratividade de um projeto de EAD, sobretudo o seu retorno e estabilidade. Muitas vezes os projetos são inviabilizados ainda na fase de planejamento, tornando-os insustentáveis. Um dos pontos que bem merece ser destacados é a ocorrência de erros na implementação dos projetos, que muitas vezes resulta no não cumprimento das metas estabelecidas. A eficiência no planejamento do projetos propicia a tomada de decisões mais eficazes, diminuindo o improviso e potencializa a equipe envolvida.

Nos projetos de EAD o processo de aprendizado do estudante é mais complexo entre outras razões por Marchetti et. al. (2005): (i) Anseios e Intenções: os estudantes a distância têm uma variedade de razões para fazer um curso que vai desde a necessidade de obtenção de um grau até a atualização de conhecimento (ii) Estilos e Ritmos de Aprendizagem: podem ser cooperativo, competitivo, ou individualizado. Um aspecto decisivo é que cada pessoa tem seu modo preferido de aprender, isto é, seu próprio estilo de aprendizagem. (iii) Estratégia de ensino e administração de tempo de estudo: uma das grandes dificuldades é estabelecer o conteúdo e seqüência que motive o estudante e o leve a auto-aprendizagem; (iv) Suporte ao 


\section{METODOLOGIA PARA PLANEJAMENTO EM EAD UTILIZANDO ESTILOS DE APRENDIZAGEM, INTELIGENCIAS MULTIPLAS E COMPETENCIAS REQUERIDAS: UMA CONTRIBUIÇÃO AO APERFEIÇOAMENTO DE EMPREENDEDORES}

aluno: uma vez que cada indivíduo possui, além da sua preferência, ritmos de aprendizagem diferentes, definir e delimitar o suporte ao aluno é uma das principais características de sucesso dessa modalidade; (v) Avaliação da aprendizagem. Isto vem confirmar a relevância de se conhecer os EA de cada indivíduo com vistas a um planejamento adequado em projetos desta natureza.

Mas, tradicionalmente, a fase de planejamento é elaborada sem levar em conta o outro lado, o usuário do sistema. É essencial considerar as formas de aprendizagem do usuário. Cada indivíduo tem a sua forma de processar informações, de perceber, pensar e resolver problemas. As individualidades, as preferências e os conhecimentos prévios dos estudantes são quase sempre ignorados. As pessoas aprendem de formas diferentes (FELDER e SOLOMAN, 1996). Alguns têm facilidade com teorias e modelos matemáticos, outros atentam mais para fatos e dados concretos. Há outros que respondem melhor à informações visuais, como figuras e diagramas, enquanto alguns preferem formas faladas e escritas. $\mathrm{O}$ conhecimento destes diferentes estilos visa contribuir rumo a uma melhor alocação dos recursos e alcance dos objetivos, os quais a EAD se orienta. Aos "olhos“ do professor, é essencial na definição de uma estratégia mais adequada para o ensino-aprendizagem. Á luz do estudante, o conhecimento dos EA vislumbra-se em mudanças nas perspectivas individuais, como motivação, atitude e comportamento e, na perspectiva profissional, o aperfeiçoamento das competências essenciais. $\mathrm{E}$ as competências em determinada atividade depende, muitas vezes, da habilidade em dosar os diferentes EA. Aliado a isto, é essencial ter conhecimento das IM pertencentes a cada indivíduo ou grupos de indivíduos. A Teoria das IM tem o potencial de expandir as diretivas curriculares a fim de visualizar todas as necessidades educacionais e pessoais de uma maneira holística, e trabalhar condutas e posturas além da habilidade técnica proposta pelos cursos de graduação (GARDNER, 1994).

O equilíbrio entre EA, as IM e as CPR é uma forma de proporcionar maiores chances de adaptação às situações do dia-a-dia ou às exigências do trabalho. Porém, como atender esta diversidade em um contexto de EAD? Configura-se assim, o objetivo deste trabalho, o qual propõe um suporte metodológico lastreado nos FCS, CPR, EA e IM, que oriente a implementação de uma estratégia de planejamento em projetos de $\mathrm{EAD}$, com vistas ao aperfeiçoamento de empreendedores. A pesquisa foi aplicada em um curso de Pós-Graduação - MBA, em Administração, do Módulo Gestão de Empreendedores, com uma amostra de 70 participantes.

\section{A PESQUISA: PASSOS E APLICAÇÃO}

O propósito desta seção é apresentar uma proposta de suporte metodológico tendo em vista dotar os gestores de projetos de EAD, de informações, permitindo-lhes : (a) monitorar o ambiente político, econômico e social, os aspectos da regulamentação, riscos que impactam direta e indiretamente o projeto; (b) melhor montagem e gerência do projeto; (c) definição de estrutura de custos; (d) definição quanto aos investimentos em projetos de EAD; e (e) definição dos resultados a alcançar. Ressalta-se que este estudo teve a sua aplicação, por meio de um questionário semi-estruturado, em Instituições de Ensino Superior Públicas e Privadas, contemplando 70 alunos, do módulo Gestão de Empreendedores. Assim sendo, com vistas a um melhor alcance no desempenho de um projeto de EAD, a proposta de metodologia 
acontece obedecendo o seguinte procedimento: inicia-se a partir da metodologia dos FCS em EAD (fase 1). Em seguida (fase 2) determinam-se os CPR (Contadores). Posteriormente determinam-se os EA dos alunos (fase 3). Por fim (fase 4), determinam-se as IM dos alunos, e encerra-se priorizando, por importância, as CPR em relação aos FCS, em seguida os EA e IM em relação as CPR.

\subsection{Fase 1: Identificação dos Fatores Críticos de Sucesso (FCS) em EAD}

Visa esta fase identificar os FCS de projetos em EAD. Os FCS “são aquelas poucas áreas, para qualquer negócio, nas quais os resultados, se satisfatórios, irão assegurar um desempenho competitivo e de sucesso para a organização” (ROCKART, 1979). Os FCS têm sido aplicados em organizações por diversas razões (Stollenwerk, 2001), como por exemplo, refinar mapas mentais e apoio na definição das habilidades, tecnologias e conhecimentos considerados essenciais pelas organizações para o alcance de desempenho superior em determinado ramo de atividade. A a identificação dos FCS acontece a partir de uma vasta seleção de achados na literatura nacional e internacional sobre EAD, especialmente (mas não exclusivamente) daqueles que envolvem o setor de Administração. Uma vez identificados os FCS sugere-se como instrumento de apoio para avaliação o modelo de escalagem dos julgamentos categóricos formulado por Thurstone em 1927 (SOUZA, 1988). A aplicação desse método objetiva explicar a estrutura de preferências dos especialistas em relação ao conjunto de estímulos, no caso, os FCS. As manifestações de preferências ocorrem em instantes diversos, e dessa forma, os valores de escala variarão em função da própria dinâmica de seu processo mental. O resultado das preferências é, então, apresentado em ordem crescente de importância.

Ao longo desta investigação foram filtrados diversos FCS da EAD. Após a identificação dos FCS e para sua melhor compreensão, estes foram reagrupados por "clusters", atendendo ao princípio da arborescência, que permite o desdobramento dos FCS em diferentes processos ou áreas envolvidas, mas observando-se sempre as relações de pertinência. Foram adotados os seguintes grupos de fatores: a) Político/Jurídico; b) Técnico; c) Econômico e Financeiro e d) Mercadológico. Detalham-se a seguir tais FCS.

Fator Técnico - Pretende-se com este fator, conhecer o comportamento no que tange a questões técnicas como, os instrumentos de apoio a construção dos projetos de EAD. O desenrolar destes projetos envolvem procedimentos complexos e exigem o domínio técnico de diversos processos tecnológicos, contratuais (jurídicos), financeiros e políticos. Questões relevantes são aqui descritas como, avaliação das necessidades dos usuários da EAD; montagem do projeto, desenho do projeto, dos contratos, a avaliação de projetos, a operacionalização de processos, coordenação e gestão de projetos, entre outras.

Fator Mercadológico e Negócios - incluem-se aqui, as questões que tangem o mercado da EAD tais como: usuários, nível de serviços, a oferta, a demanda, os aspectos macroeconômicos que influenciam nos negócios (projetos), os atores envolvidos, como os, as decisões governamentais, a política de investimentos, a política de risco entre outros. Ao se fazer uma análise dessas questões individual como em conjunto, permite-se saber o que está acontecendo com este fator e como esta situação afeta o desempenho do projeto. Dada a evidência que se coloca viabilizar projetos de EAD, tais variáveis hão de ser consideradas no contexto que permeiam as decisões de EAD. 


\section{METODOLOGIA PARA PLANEJAMENTO EM EAD UTILIZANDO ESTILOS DE APRENDIZAGEM, INTELIGENCIAS MULTIPLAS E COMPETENCIAS REQUERIDAS: UMA CONTRIBUIÇÃO AO APERFEIÇOAMENTO DE EMPREENDEDORES}

Fator Econômico e Financeiro - Ao definir este fator, busca-se conhecer questões referentes ao comportamento / tendências sobre as questões econômica e financeiras, como: política econômica do governo, indicadores econômico e financeiro, mercado financeiro, política de risco, estrutura de custos, entre outros. Ao ter estas informações, assegura-se alguns pontos para permitir a adequabilidade do projeto, como, garantia do melhor desempenho econômico possível do projeto; a manutenção permanente do equilíbrio financeiro; e uma política equilibrada de endividamento.

Fator Jurídico - Com a definição do "cluster” jurídico e seus componentes pretende-se conhecer os aspectos institucionais e jurídicos mais relevantes, as legislações, as regulamentações, as alterações na legislação, etc. Visa-se, mais especificamente, dispor de informações referentes às questões que afetam o desempenho dos projetos, como as questões jurídico-institucionais, as garantias contratuais, os direitos / deveres dos consumidores, a defesa da concorrência, e o cumprimento da responsabilidade social. Tais informações obtidas referentes a este fator vêm assegurar a adequabilidade jurídico-institucional dos projetos.

Fator Político - em termos gerais, esse bloco procura "abranger” os seguintes temas críticos: mudanças institucionais na política de educação, na política de investimentos, e nas diretrizes e objetivos governamentais no que tange o planejamento estratégico do País. Mais especificamente, é preciso dispor de informações referentes aos mecanismos viabilizadores de investimentos; a contenção das crises políticas etc. Ao se fazer uma análise da informação tanto individual como em conjunto, permite-se saber o que está acontecendo com este fator e como esta situação afeta o desempenho do projeto. Uma vez identificados os FCS, identificam-se as CPR (fase 2).

2.2. Fase 2: Determinação das competências profissionais requeridas: Esta etapa visa determinar as CPR do Administrador. Para tanto foi utilizada a Metodologia Delphi, proposta por Santos (2001), a qual é composta por quatro etapas: (i) Criação de grupo de especialistas; (ii) desenvolvimento da primeira rodada; (iii) desenvolvimento da segunda rodada; (iv) desenvolvimento da terceira rodada; e (v) desenvolvimento da quarta rodada. A seguir são descritas as etapas desta metodologia.

1. Criação do grupo de especialistas: Esta etapa tem por finalidade desenvolver a montagem do grupo de especialistas.

2. Desenvolvimento da primeira rodada: Nesta etapa cada especialista do grupo recebe uma folha de papel para responder, sem trocar idéias com o grupo, a seguinte pergunta: 'Quais são as competências que devem configurar o conteúdo do cargo X?' Posteriormente a lista é consolidada e ocorre a eliminação de repetições ou semelhanças e o resultado é registrado em uma tabela.

3. Desenvolvimento da segunda rodada: Já nesta etapa cada especialista recebe separadamente uma folha de papel em que consta a matriz de competências definida na rodada anterior. Em seguida é feita a seguinte pergunta: 'Você concorda com essas competências? Tais competências correspondem exatamente às necessárias para ocupar esse cargo?' Os especialistas devem marcar com 'N' aquelas com as quais não concorda. Em seguida calcula-se o nível de concordância.

4. Desenvolvimento da terceira rodada: Nesta etapa é feita a pergunta 'Que peso você atribuiria a cada uma das competências com o objetivo de ordená-las de acordo com o seu grau de importância para um excelente desempenho?' Os especialistas devem atribuir peso 01 
(um) para a competência mais importante e aumentar o valor do peso à medida que a competência avaliada torna-se menos importante. Não deve ser atribuído o mesmo peso para mais de uma competência.

5. Desenvolvimento da quarta rodada: Com base nos resultados obtidos na etapa anterior, a próxima pergunta feita aos especialistas é: 'Você concorda com as ponderações obtidas? Reflita cuidadosamente. Você muda ou mantém suas ponderações?'

A principal aplicação do Método Delphi é a busca pelo consenso da opinião de um grupo de especialistas; a premissa básica é que o julgamento coletivo, quando organizado adequadamente, é melhor do que a opinião individual. Outra vantagem é a possibilidade de uma abordagem interdisciplinar (MÂSIH, 2005).

Destacam-se algumas competências e habilidades que o Contador deve desenvolver ao longo de sua formação, dentre elas (FLEURY e FLEURY, 2000): (i) Competências de Negócios ;; (ii) Competências Sociais ; e (iii) Competências Técnicas.

\subsection{Fase 3: Identificação dos Estilos de Aprendizagem dos alunos}

Nesta fase objetiva-se identificar os EA dos alunos (participantes do curso). Para isto, foi utilizado o inventário de Felder e Saloman (1996), derivado do modelo desenvolvido por Felder e Silverman (1988), o qual é direcionado para as características de aprendizagem. Este instrumento de coleta de dados, denominado Índice de EA (Index of learning styles - ILS), classifica os estudantes em quatro das dimensões: (i) (Sensorial / Intuitivo): refere-se a forma como a informação é percebida; (ii) (Visual / Verbal): indica o modo de retenção da informação; (iii) (Ativo / Reflexivo): revela o maneira de processar a informação; (iv) (Seqüencial / Global): apresenta a forma de organização da informação. Os resultados apontam a dimensão dominante entre os cinco pares, que são expressas em escalas: leve, moderada e forte. O ILS é um instrumento auto-aplicável que identifica as preferências de aprendizagem do respondente. É composto de 44 questões de escolha forçada, 11 para cada uma das quatro dimensões de aprendizagem abrangidas pelo instrumento. Os resultados são apresentados em termos de cada uma das dimensões. O inventário foi aplicado (conforme já mencionado) a alunos de ambos os sexos, do curso de Pós-Graduação/MBA, Gestão de Empreendedores, em 70 alunos. Foram mapeados os EA de 70 alunos. Os resultados obtidos na pesquisa são detalhados na Figura 1 a seguir. 

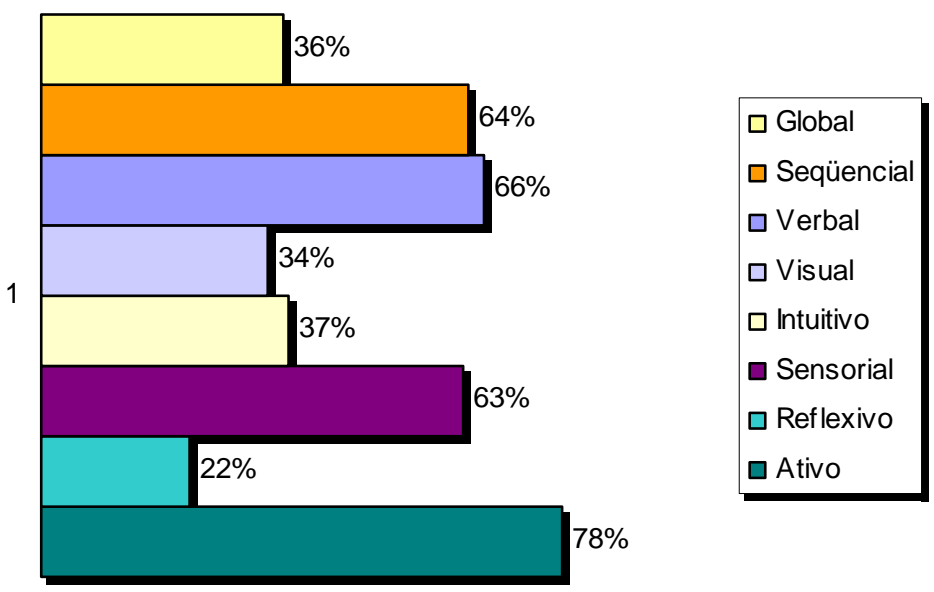

Figura 1 - Estilos de Aprendizagem geral dos Alunos

A Figura 1 apresenta o perfil predominante dos alunos, baseado no modelo de Felder e Soloman (1996) Ativo (78\%), Sensorial (63\%), Verbal (66\%), Seqüencial (64\%). A predominância do estilo Ativo/Seqüencial aponta que o aluno prefere executar, praticar, resolver situações problemas reais. Participa efetivamente de discussões, principalmente das que envolvem aspectos práticos de um problema concreto, daí sua maior propensão em apresentar bom desempenho no trabalho em equipe e gosta de aprender de forma contínua, ou seja, passo a passo. Uma vez levantados os EA, a fase (4) seguinte consiste em determinar as IM dos alunos.

\subsection{Fase 4: Determinação das Inteligências Múltiplas}

Esta fase contempla as Inteligências Múltiplas dos alunos de EAD nos cursos de PósGraduação/MBA, Administração - Gestão de Empreendedores das instituições pesquisadas. A Teoria das IM tem como proposta o desenvolvimento de um indivíduo, considerando habilidades específicas e estimulando a capacidade de assimilação de conteúdos de forma natural, assim como a habilidade de resolver conflitos pessoais e profissionais de forma equilibrada e a capacidade de trabalhar em equipe, dentre outras. Essa Teoria é mais um instrumento nas mãos daqueles que ensinam com vistas a facilitar a execução das práticas de ensino e seu planejamento, tendo como referencial, além do conteúdo e estratégias, o alcance dos objetivos propostos pela disciplina. Os tipos de Inteligências Múltiplas aqui consideradas foram extraídas a partir da proposta de GARDNER (1994): Lingüística, Musical, LógicoMatemática, Espacial, Cinestésico-Corporal, Intrapessoal e Interpessoal. Os resultados são apresentados na Figura 2 a seguir. 


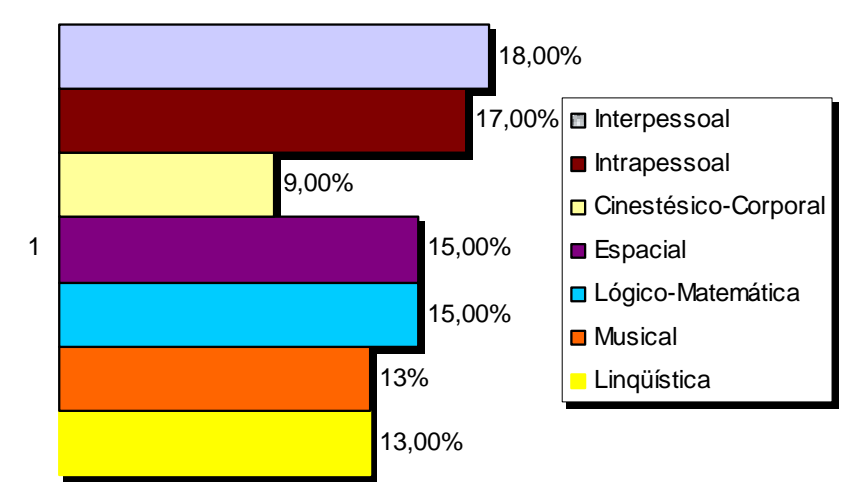

Figura 02: Inteligências Múltiplas - Alunos - EAD

Reunindo aqui as diversas dimensões de Inteligências, os resultados mostram (Figura 02) que não há grandes predominâncias de um ou outro tipo de Inteligência, com ênfase para as Inteligências Pessoais (18\% e 17\%), e exceção para a categoria Cinestésico-Corporal (9\%). Alinhado a isto, abre-se um espaço rumo a definição de novas estratégias de planejamento de ensino a serem adotadas. Há de se ter em mente que tais estratégias devem ser orientadas com vistas a alcançar alunos que assumem os seguintes perfis: Gostam de ler e escrever, explicar, ensinar, memorizar, reconhecer padrões abstratos, raciocínio indutivo e dedutivo, discernimento de relações e conexões, preferências por experimentos, soluções de cálculos complexos, imaginação ativa, reconhecimento de relações entre objetos e espaços, representação gráfica e manipulação de imagens, capacidade de abstração e raciocínio, senso de autoconhecimento, concentração total da mente, trabalho cooperativo, entendimento da perspectiva do outro, comunicação verbal e não-verbal, capacidade de liderança e motivação e percepção e distinção dos diferentes estados emocionais do outros etc.

Uma vez levantados, os FCS, CPR, os EA e as IM, priorizam-se, por importância, as CPR em relação aos FCS. Em seguida, os EA e as IM em relação às CPR. Com vistas a reduzir a subjetividade dos resultados apresentados, adotam-se os métodos multicriteriais Compromise Programming, Electre III e Promethee II . Os resultados deste cruzamento permitem aos planejadores de EAD estabelecer diretrizes na política de implementação de um projeto de EAD aliada aos FCS (Figura 3). 
METODOLOGIA PARA PLANEJAMENTO EM EAD UTILIZANDO ESTILOS DE APRENDIZAGEM, INTELIGENCIAS MULTIPLAS E COMPETENCIAS REQUERIDAS: UMA CONTRIBUIÇÃO AO APERFEIÇOAMENTO DE EMPREENDEDORES

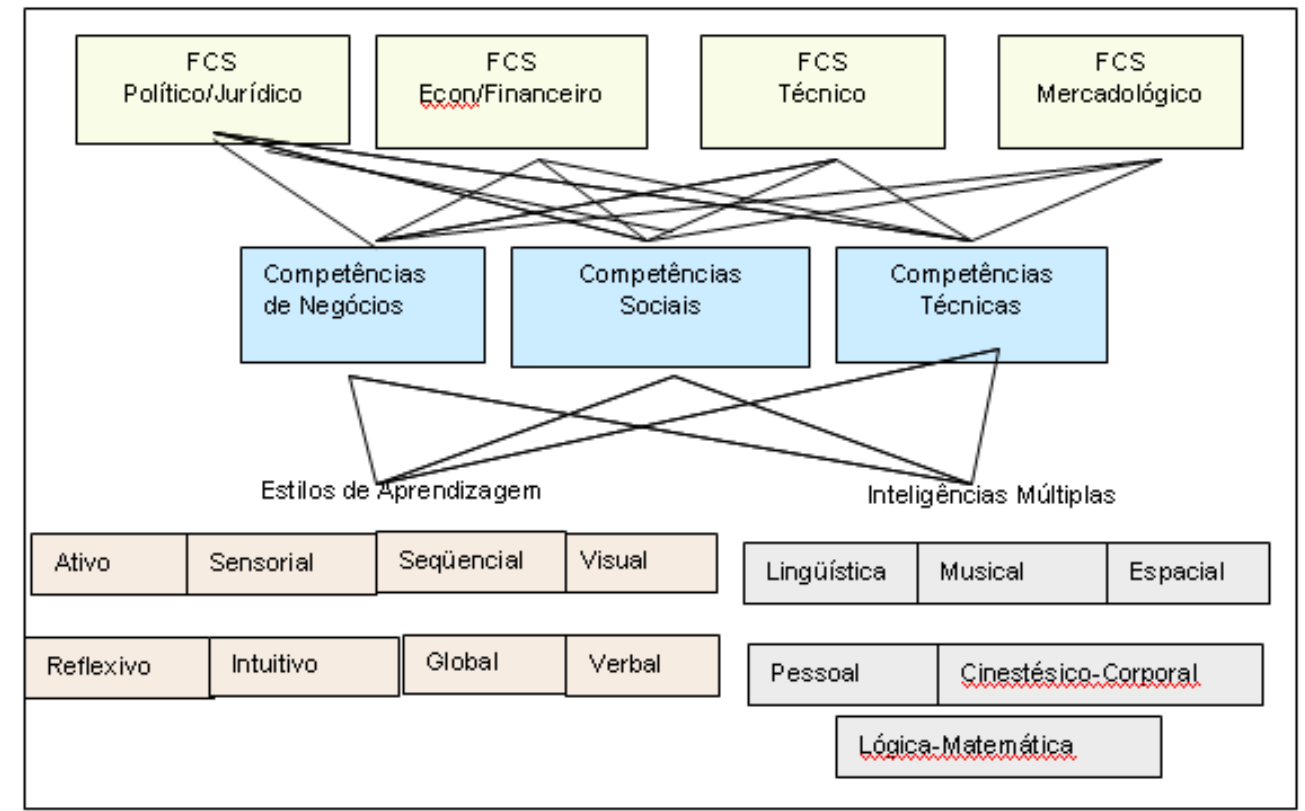

Figura 3: Prioridades por importância: Competências em relação aos FCS; EA em relação às CPR; IM em relação às CPR.

\section{DISCUSSÃO DOS RESULTADOS}

Na visão dos especialistas, no que diz respeito a relaçao CPR e FCS, os resultados mostram uma maior importância das competências de Negócios para assegurar os FCS Político e Mercadológico. E apontam as competências Técnicas para assegurar os FCS Econ/Fin e Técnico. Significa que há uma maior necessidade dos gestores de EAD concentrarem maiores esforços nestas competências com vistas a assegurar os referidos FCS.

Sobre os resultados das prioridades dos EA em relação às CPR, na visão dos especialistas, para assegurar as competências de Negócios é notável que o indivíduo contemple Estilos de Aprendizagem predominantemente Ativo/Global/Verbal/Intuitivo. Sobre esses indivíduos, pode-se dizer que têm a capacidade de absorver a informação em grandes saltos holísticos. Fragmentos aparentemente sem conexão repentinamente se ligam, para formar o grande quadro, e tudo fica claro. Precisa enxergar o contexto em que a situação ocorre, para então compreender como juntar as partes para resolver o problema. Tem facilidade para "juntar conhecimento" de maneiras inovadoras, para resolver problemas de formas criativas, mas pode ter alguma dificuldade para explicar seu raciocínio; pois seu foco está na síntese, no pensamento sistêmico, e não na linearidade. O global pode ter dificuldade para trabalhar em atividades em que não enxergue o objetivo final pretendido. Da mesma forma, um treinamento seqüencial, linear, bem organizado, mas descontextualizado pode ser encarado como ineficiente. Além disso, são indivíduos que tendem a compreender e reter melhor a informação participando ativamente da realização de uma atividade. No que diz respeito ao estilo Ativo, de uma forma geral são estes preferem executar, praticar, resolver situações problemas reais. Participa efetivamente de discussões, principalmente das que envolvem aspectos práticos de um problema concreto, daí sua maior propensão em apresentar bom desempenho no trabalho em equipe. Normalmente é rápido nas respostas e movimentos, mas em decorrência pode agir prematuramente, sem ter avaliado conseqüências e impactos. 
Recomenda-se, portanto, que, por exemplo, ao participar de uma atividade (aula, reunião de negócios, comitê) em que não é enfatizada a discussão de um problema prático ou sua solução, é interessante que se compense essa divergência com seu estilo de aprendizagem preparando-se antes, tentando prever as decisões e suas conseqüências. Trabalhar ou estudar com um grupo, no qual os integrantes expliquem diferentes tópicos uns aos outros. Procurar antever o que lhe possa ser perguntado, levantar diferentes cenários e estabelecer planos de ação.

Num segundo momento, salienta-se a importância dos EA Ativo/Sensorial/Seqüencial/Visual para assegurar as Competências Técnicas. Sobre esses EA. Conforme já discutido, são indivíduos que tendem a compreender e reter melhor a informação participando ativamente da realização de uma atividade. O ativo prefere executar, praticar, resolver situações problemas reais. Participa efetivamente de discussões, principalmente das que envolvem aspectos práticos de um problema concreto, daí sua maior propensão em apresentar bom desempenho no trabalho em equipe. Normalmente é rápido nas respostas e movimentos, mas em decorrência pode agir prematuramente, sem ter avaliado conseqüências e impactos.

Sobre as prioridades das IM em relação às CPR, enfatiza-se a importância das IM Pessoais para assegurarem as Competências Sociais, de Negócios e Técnicas. Salienta-se ainda, um destaque para a Inteligência Lingüística para assegurar as Competências de Negócios, Técnicas e Sociais. De fato, a Inteligência Lingüística é a capacidade de lidar bem com a linguagem, tanto na expressão verbal quanto escrita. Esta inteligência pode ser considerada como o melhor meio para executar negocios, tarefas e comunicar acontecimentos. Conforme mencionado anteriormente são características de pessoas que têm este tipo de inteligência : gostar de ler, escrever, explicar, ensinar e aprender, convencer alguém sobre algum fato e memorizar.

Já as Inteligências Pessoais - intrapessoal (envolvida principalmente no conhecimento que o indivíduo faz de seus próprios sentimentos) e interpessoal (relacionada à atuação de comportamentos, sentimento e motivação em relação aos outros) - são mais fáceis de serem interpretadas quando comparadas (GARDNER, 1994). A característica básica de uma pessoa que possui esta inteligência é a de estar bem consigo mesmo, administrando o próprio humor, os sentimentos, as emoções, os projetos, etc, tudo isso coerentemente, dentro de um contexto social e profissional. Algumas características de pessoas que possuem este tipo de inteligência são, conforme mencionado anteriormente: senso de autoconhecimento, capacidade de abstração e raciocínio, percepção e expressão de diferentes sentimentos íntimos etc.

\section{PALAVRAS FINAIS: Que lições tirar?}

Enormes são as demandas por informações e conhecimentos. A capacitação é um processo sistemático e contínuo de avaliação das necessidades futuras de recursos humanos. Esse processo deve resultar em pessoas com habilidades, experiências e competências adequadas para desempenhar as tarefas corretas no local e momento oportuno. Neste espectro, a perspectiva da eficiência da gerência da EAD deve estar balizada em métodos e técnicas que permitam um planejamento correto rumo às decisões a serem tomadas. 


\section{METODOLOGIA PARA PLANEJAMENTO EM EAD UTILIZANDO ESTILOS DE APRENDIZAGEM, INTELIGENCIAS MULTIPLAS E COMPETENCIAS REQUERIDAS: UMA CONTRIBUIÇÃO AO APERFEIÇOAMENTO DE EMPREENDEDORES}

Encerra-se este documento sobre EAD no campo da Administração, sobretudo a gestão de empreendedores, evidentemente permanecem diversas questões a serem aprofundadas em outros estudos do gênero. Para estes novos estudos espera-se ter contribuído para discussão metodológica que ainda pode ser bastante explorada. Crê-se ainda na importância de se entender a EAD no sentido das necessidades da sociedade. Necessidades estas criadas no seu devido contexto social, econômico e político.

É de salientar que a EAD no Brasil ainda é uma tarefa científica mal começada. Embora se possa enumerar uma quantidade de títulos já disponíveis sobre o assunto, poucas obras se prestam para a construção sistemática da experiência brasileira no setor.

No que tange aos métodos e técnicas para viabilizar EAD, o Brasil ainda encontra-se em situação de desvantagem quando se compara às experiências internacionais: é carente em aportes materiais, tecnológicos e humanos. O conhecimento é insuficiente, e o capital intelectual é despreparado. O que torna insustentável viabilizar projetos tão relevantes. É nesse panorama que a nossa contribuição metodológica ganha ênfase, à medida em que há um apoio das prioridades críticas a serem consideradas no rol de elementos necessários à implantação de um projeto desta natureza, contribuindo para a construção do capital intelectual, como elemento estratégico na Gestão de Empreendedores.

Busca-se ainda, por meio deste método, uma orientação mais pragmática e eficiente subsidiando as diretrizes para o desenvolvimento dos projetos de EAD no longo prazo, garantindo a competitividade nacional no que tange a essa categoria de projetos. Hão de se procurar abordagens amplas e sistêmicas, capazes de reunir as mais diversas dimensões sobre EAD, superando-se a prática pouco científica que permeia ainda algumas obras.

Essa proposta visa, antes de tudo, que se iluminem questões ainda não exploradas neste objeto tão-complexo. Evidentemente, não pretende ser uma "camisa de força" metodológica, mas que venha prestar uma contribuição, mesmo que por caminhos mais livres. Além disso, esse suporte metodológico não tem a pretensão de ser completo, mas sim, de ser gerador de elementos do conhecimento que são estratégicos para o desenvolvimento de projetos de EAD. O que torna o espectro de decisão mais inteligente, disponibilizando elementos essenciais para a elaboração de projetos de EAD. Muitas vezes esses projetos são inviabilizados, fracassando ainda na fase de planejamento.

À luz dos "Estilos de Aprendizagem, das Inteligências Múltiplas e das Competências requeridas" foi possível desenvolver a proposta de uma metodologia que tem por propósito contribuir nas diretrizes de alocação dos aportes de recursos, para a construção do capital intelectual no campo da Contabilidade.

Reconhece-se ainda a relevância dos FCS como mais um importante instrumento de estratégia nas mãos dos gestores de EAD, pois poderão contribuir na priorização dos pontos fracos, evitando ser deficiente naquilo que é relevante para o sucesso do negócio (THOMPSON e STRICKLAND, 2000).

Por se tratar de uma temática tão relevante no contexto histórico atual de nosso País, recomenda-se que este estudo, dada a factibilidade demonstrada do método, seja continuado e atualizado de forma permanente e recorrente, permitindo o acompanhamento das mudanças ocorridas no contexto que se insere os projetos de EAD. 


\section{REFERÊNCIAS}

CARVALHO, A.V. Treinamento: princípios, métodos e técnicas. S. P.: Pioneira, 2001.

FELDER, R.M.; SALOMAN, B.A. Index of Learning Styles'. Disponível em: $<$ http://www.ncsu.edu/felder-public/ILS.Spage.html>. Acesso em 25 agosto de 2006

FELDER, R.M.; SILVERMAN, L.K. Learning and teaching styles in engineering education. Journal of Engineering Education, v. 78, n. 7, p.674-681, abr.1988.

FLEURY, A.; FLEURY, M. T. L. Estratégias empresariais e formação de competências. São Paulo: Atlas, 2000.

GARDNER, H. Estruturas da mente : a teoria das inteligências múltiplas. São Paulo, Artes Médicas, 1994.

KAYE, A. Analysing Distance Learning Systems. Londres: Open University, 1979.

LAASER, W. et al, Manual de criação e elaboração de materiais para educação a distância. Brasília:CEAD; Ed. Universidade de Brasília, 1997.

LEVY, S. Six factors to consider when planning online distance learning programs in higher education. Disponível em: http://www.e-mentor.edu.pl/. Acesso em 23/03/2007.

MARCHETI; A.P.C.; BELHOT; R.V., SENO, W.P. “Educação à Distância: diretrizes e contribuições para a implantação dessa modalidade em instituições educacionais”. Revista Digital da CVA - RICESU - vol.3 - nº - julho de 2005.

MÂSIH, R.T. Um método para modelagem das competências individuais vinculadas à estratégia empresarial por meio do Balanced Scorecard. Tese de Doutorado (Programa de Pós-Graduação em Engenharia de Produção). Florianópolis: UFSC, 2005.

ROCKART, J. F. Chief executives define their own data needs, Harvard Business Review (1979).

SANTOS, A.O. O uso do método Delphi na criação de um modelo de competências. Revista da Administração. Vol. 36, No. 02, pp. 25-32, abril/junho 2001.

SOUZA, J. Métodos de Escalagem Psicossocial. Vol. V, Brasília: Thesaurus, 1988.

STOLLENWERK, M. F. L. Fatores Críticos de Sucesso. Ed. UnB. Brasília-DF (2001)

THOMPSON, A. A. E STRICKLAND, A. J. Planejamento estratégico: elaboração implementação e execução. Editora Pioneira, São Paulo, 2000. 